\title{
Mental health rehabilitation in a care farm context: A descriptive review of Norwegian intervention studies
}

\author{
Ingeborg Pedersen ${ }^{\mathrm{a}, *}$, Grete Patil $^{\mathrm{a}}$, Bente Berget ${ }^{\mathrm{b}}$, Camilla Ihlebæk $^{\mathrm{a}}$ and Marianne Thorsen Gonzalez \\ ${ }^{a}$ Section for Public Health Science, Department of Landscape Architecture and Spatial Planning \\ Norwegian University of Life Sciences, Ås, Norway \\ ${ }^{\mathrm{b}}$ Department of Animal and Aquacultural Sciences, Norwegian University of Life Sciences, Ås, Norway \\ ${ }^{\mathrm{c}}$ Institute of Nursing and Health, Diakonhjemmet University College, Oslo, Norway
}

Received 4 August 2014

Accepted 5 August 2014

\begin{abstract}
.
BACKGROUND: Care farming is a service developed at farms for promoting mental and physical health and is increasingly used in mental health rehabilitation in Norway.

OBJECTIVE: This article aims to present a descriptive review of Norwegian intervention research on care farms that provide rehabilitation for people with mental health disorders.

METHODS: This literature review applied a non-systematic search strategy: all articles in the field known to the authors were selected for inclusion. The selected studies were intervention studies that were conducted on farms in Norway, that used adult participants with mental health problems/disorders, and that reported outcome measures related to mental health. The studies and articles presented quantitative and/or qualitative data.

RESULTS: The findings from the published articles report improvements to mental health problems, such as depression, anxiety, perceived stress, positive affect, rumination, and self-efficacy. Qualitative data describe a variety of positive experiences, such as improved coping ability, increased social support, and appreciation of the care farm activity.

CONCLUSION: Participating in interventions on care farms positively influences mental health. Care farming may therefore be used as a supplementary approach in mental health rehabilitation, as it offers meaningful and engaging occupations and social inclusion.
\end{abstract}

Keywords: Animal-assisted interventions, care farming, meaningful occupations, therapeutic horticulture

\section{Introduction}

People with mental health disorders tend to suffer from stigmatization, low quality of life, isolation, loneliness, and low self-esteem [1-4], and they are often

\footnotetext{
*Address for correspondence: Ingeborg Pedersen, Norwegian University of Life Sciences, Section for Public Health Sciences, Department of Landscape Architecture and Spatial Planning, P.O. Box 5003, NO-1432 Ås, Norway. Tel.: +47 672312 65; Mobile: +47 90502 902; E-mail: ingeborg.pedersen@nmbu.no.
}

excluded from ordinary work [5]. Participating in a meaningful, daily occupation has been shown to be especially important for people in such a situation, as through work, they can obtain positive experiences, like feeling needed, getting support and understanding, and having a purpose in daily life [6-8]. Previous studies have also shown that having an occupation leads to lessened symptoms of mental health disorders $[9,10]$. The main aim of mental health rehabilitation is to help individuals suffering from mental health disorders to 
develop the skills they require to live independent lives in the local community, with employment in vocational occupations as a vital element [11].

Daily occupation, social inclusion, belonging, and social support are issues brought forward as important both by participants and professionals during studies of rehabilitation [6, 12-15]. Enhanced social skills, work performance, and work-related self-efficacy, as well as social support during rehabilitation, are also seen as important factors for successful transition into employment $[11,16,17]$. Care farming is a service that has developed within the agricultural sector in Europe [18]. It aims to promote mental and physical health [19], and in Norway, it is increasingly used in mental health rehabilitation. The main idea of care farming rehabilitation is that people in need of health-related support may on a regular basis participate in farm-related activities alongside a farmer. Most commonly, these are group activities, but they should always be adapted to each individual participant's mental and physical needs. Several studies on care farming highlight group participation, the social setting, and the farmer's supportive supervision as important [20-23]. Furthermore, earlier qualitative studies have described care farming programs as a suitable transition between marginalization related to illness and inclusion in society $[22,24]$.

Care farming is increasing in many European countries [25]. In Norway, care farming is especially well developed, and during the last few years, several intervention studies have been conducted to investigate both the possible health effects of participation on a care farm and clients' experiences. To our knowledge, no other country has carried out intervention studies on care farms to the same extent as Norway has; thus, a descriptive review of existing research related to the use of care farming in mental health rehabilitation in a Norwegian context is of interest. The aim of this article is to present a review of four studies of Norwegian intervention that took place on care farms, within the context of rehabilitation programs on care farms.

\section{Methodological approach}

This article presents a descriptive review of intervention studies of adults with mental health disorders participating in either animal-assisted interventions or therapeutic horticulture programs on a Norwegian care farms. All the authors have contributed to intervention studies on care farms in Norway. Therefore, to cover as much published Norwegian research as possible, all of the authors collected possible articles for inclusion. Four intervention studies were located on Norwegian care farms, and 10 articles from these studies have been published in peer-reviewed journals. In a descriptive way, this article will both present how the research was carried out and summarize key information from the published articles. To analyze the quantitative research, we extracted data on study aims, designs, participants, interventions, outcome measures, and main findings. To analyze the qualitative data, we reported the main themes/findings of the articles.

All articles are indexed in one or more of the following electronic databases: Cinahl, ISI Web of Science, MEDLINE (PubMed), and PsycINFO. A combination of the following keywords may be used to search for them: care farm, therapeutic horticulture, animalassisted interventions, green care, depression, mental health, and rehabilitation.

\section{Presentation of Norwegian care farm research}

The four studies consisted of two randomized controlled trials (RCT) and two single-group design studies. Six articles report research from animalassisted interventions, and four articles report research from therapeutic horticulture interventions. Of all these, one article presents qualitative data from individual interviews, and two articles present qualitative data from open-ended questions.

In the following, we will discuss the nature of this research and present its core findings related to these intervention programs and an overview of the published articles related to the study and type of intervention/program. Extracted data on key information from the articles are presented in Table 1.

\subsection{Presentation of the research: Methods, intervention and procedure}

\subsubsection{Care farming activities with animals}

The first study is an RCT study by Berget et al. [26-28]. This study examined the possible effects on mental health, quality of life, self-efficacy, and coping ability of taking part in work tasks with farm animals for people with various mental health disorders. The study included 90 participants (60 in the intervention and 30 in the control group) and was carried out at 15 farms in five Norwegian counties. The participants were recruited by their primary contact person in health care services. 


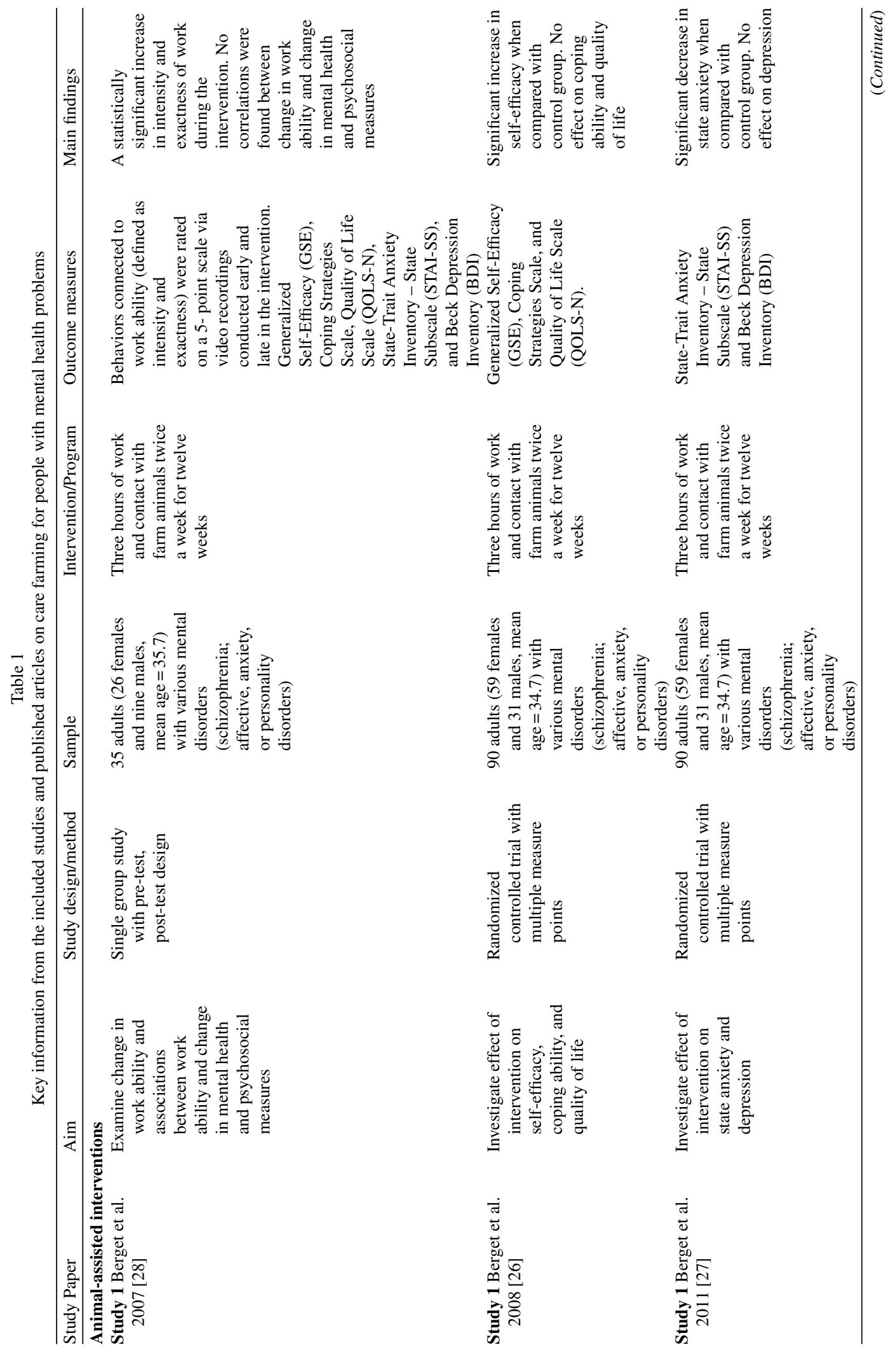




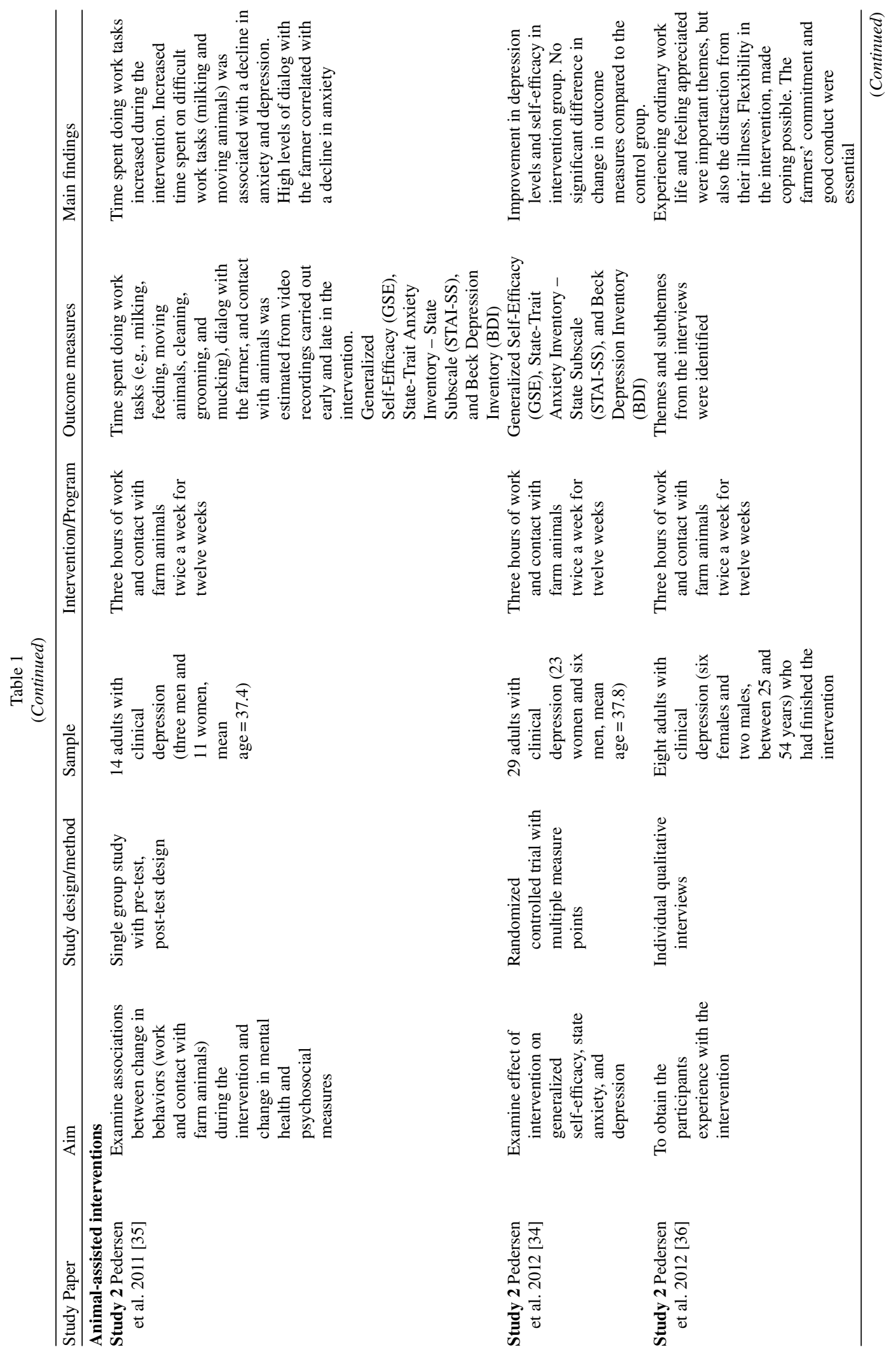




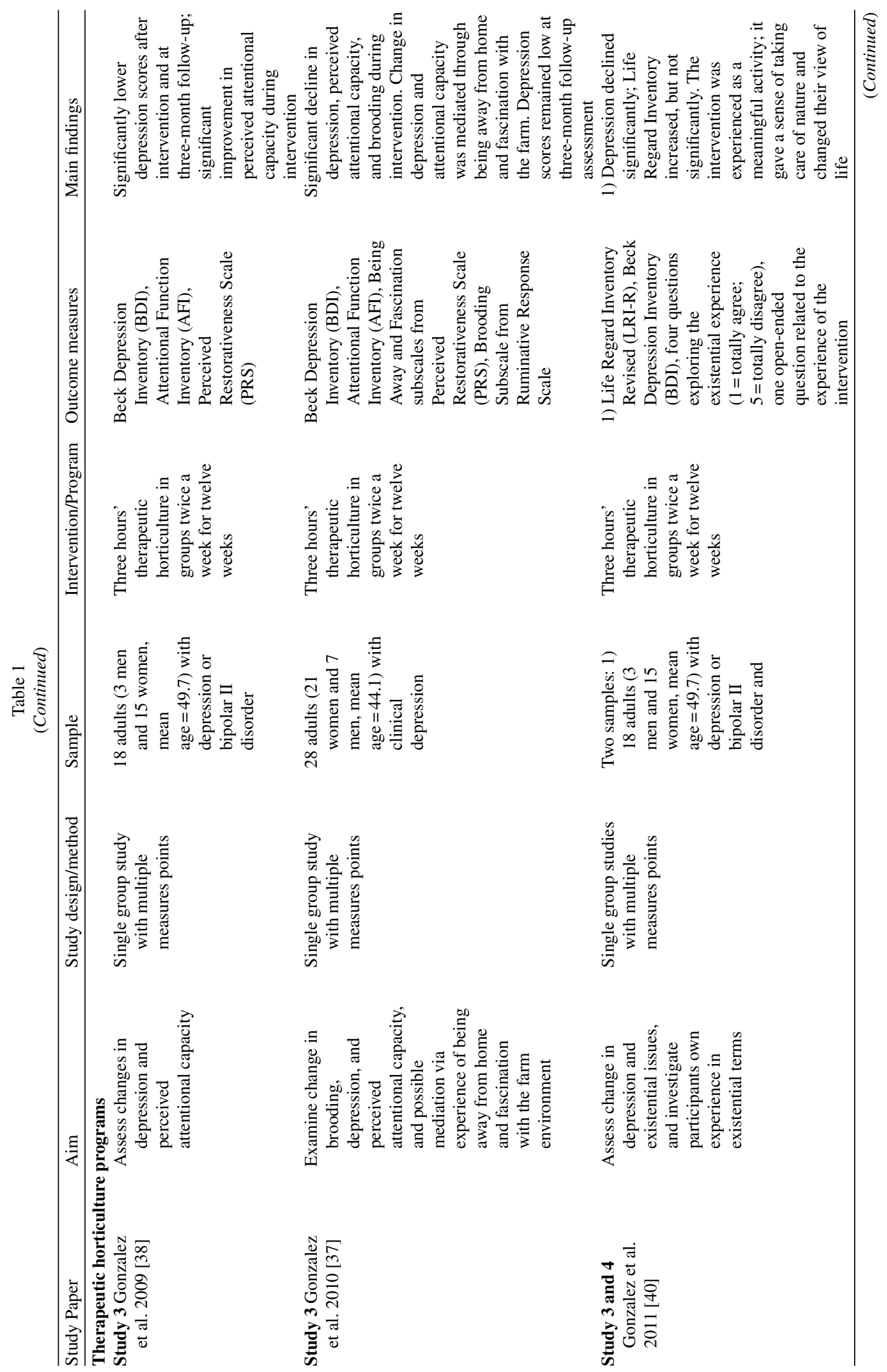




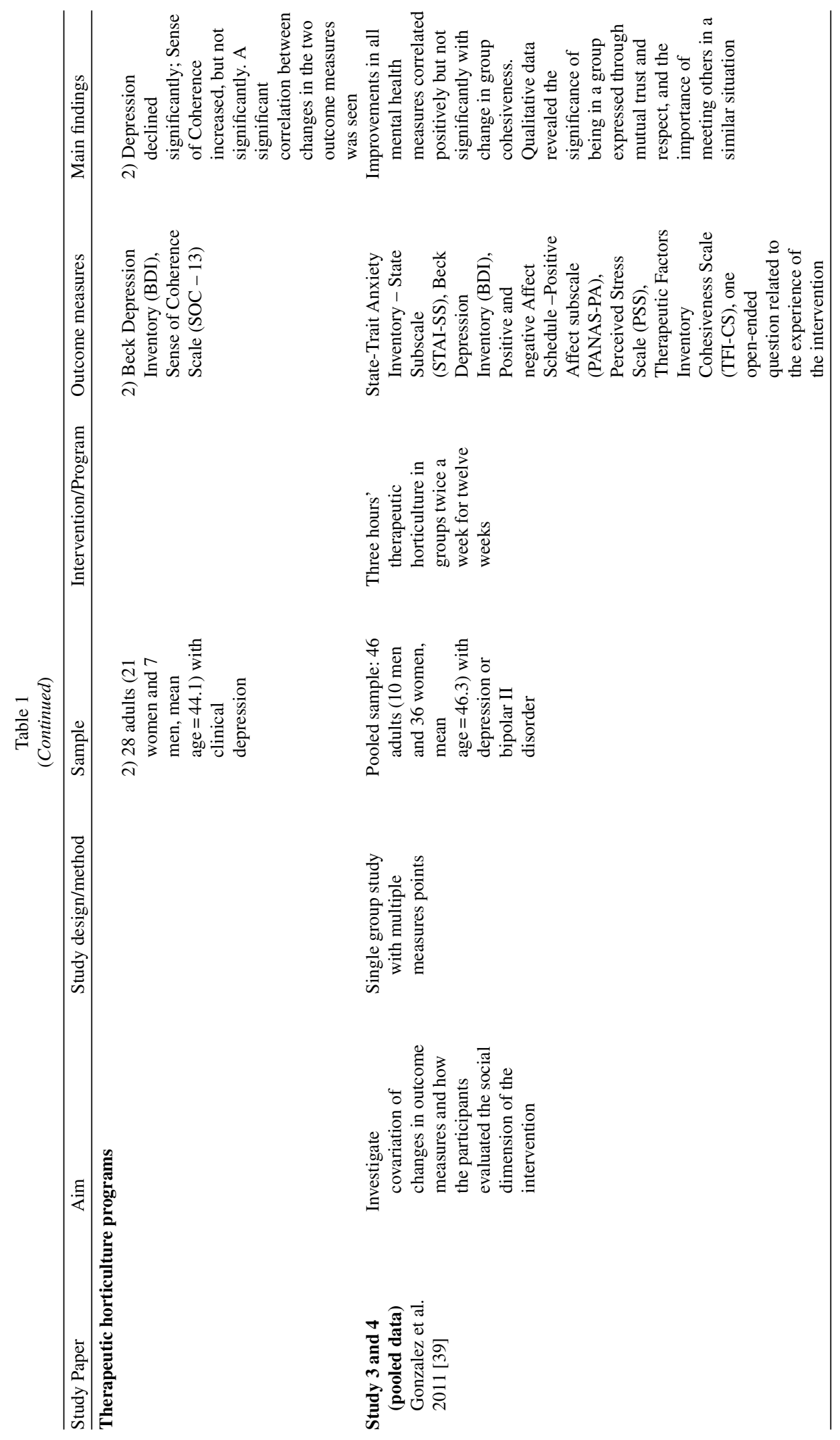


There were 41 participants completing the intervention and 28 participants completing in the control group. The participants traveled to and from the farm using public transport or their own car, or the farmer picked them up at home due to a lack of available transport or due to personal issues. Participants in the intervention group continued their ordinary treatment in addition to visiting the farm for three hours twice a week for three months. The participants in the intervention group attended the farm twice a week for twelve weeks. They were on the farm for 3 hours each time and there were 1 or 2 participants working along with the farmer at the time. They did ordinary work tasks related to the care of farm animals, like feeding, milking, grooming, or cleaning the barn. The work tasks chosen depended on each participant's capacity and interest, but they always had an opportunity for physical contact with the animals. The most common animals at the farms were dairy cows, cattle, sheep, or horses. All farms also had small animals, like rabbits, poultry, pigs, cats, or dogs, as a part of the animal milieu.

The severity of participants' anxiety was examined using the Spielberger State-Trait Anxiety Inventory - State Subscale [STAI-SS,29], the severity of their depression by using the Beck Depression Inventory [BDI,30], their quality of life by using the Norwegian version of the Quality of Life Scale [QOLS-N,31], their self-efficacy by using the Generalized Self-efficacy scale [GSE,32], and their coping ability by using the Coping Strategies Scale [Coping Strategies Scale, 33]. Scores in these self-rated measures were obtained before the intervention, at the end of the intervention, and six months after the end of the intervention.

In addition 35 participants (26 females and nine males) were videotaped for a whole session at the farm both early (during the two first weeks) and late (during the last two weeks) in the intervention period. The video recordings were used to examine whether the participants' working ability changed during the intervention through observing and measuring the intensity and exactness of the work. Intensity was measured by the speed and effectiveness of a certain work task, while exactness was measured by the quality and accuracy of the work that was performed. Both categories were scored from 1 ("very low") to 5 ("very high") in one minute intervals for the whole recording. A questionnaire related to the participants' experiences was developed. Its questions included the following: To what extent has the contact and work with the animals affected their coping ability in daily life, your mood, your self-esteem, and your working ability? A question in regard to the importance of physical contact with the animals was also a part of the questionnaire. All questions were answered on a 5-point scale from 1 ("much worse/very little") to 5 ("much better/very much").

The second study of interventions with farm animals is an RCT study by Pedersen et al. [34] in which the primary aim was to examine the effect of the intervention on depression, state anxiety, and self-efficacy among people suffering from depression and to compare the results with changes observed in a control group undergoing treatment as usual. A second aim was to examine the associations between various work tasks conducted during the intervention and changes in mental health. Finally, participants were interviewed to uncover their own experience of the intervention at the farm and what they perceived as important elements of the intervention in relation to their mental health.

Thirty-four people were recruited via health personnel, advertisement in newspapers, or letters of invitation sent via the Norwegian Labor and Welfare Administration. All participants had a Beck Depression Inventory score of 14 or above, indicating clinical depression. After giving their written consent, the participants were randomly assigned to one of two groups: an intervention group or a waiting-list control group. Some participants withdrew from the study before the interventions started, and the final sample was made up of 29 participants (23 women and 6 men).

Eleven dairy farms from six Norwegian counties took part. The majority of the participants traveled by public transport or in their own car to and from the farm, but in agreement with the farmers, some were picked up at home by the farmers, due to lack of available transport or due to personal issues. No limit was set in regard to the distance between the participants' own homes and the farms, but in practice, more than one hour of travel each way was too inconvenient. The participants in the intervention group attended the farm twice a week for twelve weeks. They usually worked alone with the farmer, but at some farms, two participants worked with the farmer at the same time. They conducted ordinary daily work tasks with farm animals (mainly cows), like feeding, cleaning, and milking.

To meet the primary aim of the study, the Beck Depression Inventory [BDI, 30] was used to measures participants' levels of depression, the Spielberger State-Trait Inventory - State Subscale [STAI-SS,29] to measures their state anxiety, and the General SelfEfficacy Scale [GSE,32] to measure their self-efficacy. The assessments were filled out by the participants at the time of their recruitment, before start of the inter- 
vention, as well as after four and eight weeks of the intervention, respectively, and at the end of the intervention. Follow-up registrations were completed after three months. In both groups, there were 12 participants who completed the study.

To examine the associations between various work tasks conducted during the intervention and changes in the participants' mental health, 14 participants in the intervention group were recorded on video while working with the animals [35]. This recording took place twice during the intervention: once at the beginning and once in the end. The recordings were categorized into different behavioral categories with respect to animal contact, conversation with the farmer, and work tasks undertaken (e.g., milking, feeding, cleaning, mucking, grooming, moving animals in free range systems). Time spent in the various behavioral categories was registered, and correlations with change in the above-mentioned mental health measures were calculated. Finally, to uncover the participants subjective experiences, thematic individual interviews were conducted with eight of the participants who had completed the intervention [36].

\subsubsection{Care farming with horticultural activities}

Gonzalez et al. [37-40] have carried out two singlegroup design studies of the possible benefits to people with clinical depression of participating in a horticultural activities on four urban farms. Both aimed to examine changes in depression and perceived attentional capacity. Further, they analyzed the possible mediating roles of the experience of being away and fascination on depression and perceived attentional capacity, as well as examining changes in anxiety, brooding, and existential issues. Another aim of their studies was to investigate the covariation of changes in outcome measures and how the participants evaluated the social dimension of the intervention. A final aim was to investigate the participants' own experiences in social and existential terms.

The two studies were carried out in 2008 and 2009. The studies both had a convenience sample of, respectively, 18 ( 3 men, 15 women) (study 1) and 28 participants (21 women and 7 men) (study 2), with the inclusion criterion of having a Beck Depression Inventory (BDI) score greater than 15 . The participants were recruited from general practitioners and through advertisements in newspapers. Potential participants contacted the researchers directly by phone.

The participants traveled to and from the farm using either public transport or their own car or bicycle, and participants were assigned to farms in such a manner that it would be convenient to travel back and forth. A group-based therapeutic horticulture program (three to seven participants in each group) was carried out over twelve weeks, during which time participants met twice a week for three hours at a time. The programs were facilitated by the farmer and included activities like sowing, germinating, potting, planting, composing beds, cultivating vegetables, picking flower bouquets, and watching birds, insects, and the landscape. The intervention supplemented the participants' regular treatment, which mainly consisted of attending psychotherapy sessions at varying frequencies, use of antidepressants, or a combination of the two. All the farms have strong historical and cultural identities, and they are all are situated in open, hilly landscapes.

Data were collected prior to, twice during, immediately after, and three months following the program. The Beck Depression Inventory [BDI,30] was used to measure depression severity, the Attentional Function Index [AFI,41] was used to measure attentional function, the Being Away and Fascination subscales from the Perceived Restorativeness Scale [PRS,42] were used to assess the perceived restorativeness of the environment, the Spielberger State-Trait Anxiety Inventory - State Subscale [STAI - SS,29] was used to measure state anxiety, the Brooding Scale [43] was used to measure rumination, the Perceived Stress Scale [PSS,44] was used to measure stress levels, the Positive and Negative Affect Scale [PANAS-PA,45] was used to measure positive affect, and the Therapeutic Factors Inventory Cohesiveness Scale [TFI-CS,46] was used to measure group cohesion. Existential issues were measured using the Life Regard Index - Revised Version (LRI - R) [47] in study 1, and were measured in the second using Antonovsky's 13-item version of the Sense Coherence Scale, developed from the original 29-item version [48, 49]. The participants answered four questions regarding the existential experiences of therapeutic horticulture on a scale from 1 ("totally agree") to 5 ("totally disagree"), as well as several open-ended questions related to the experience of participating in the program.

\subsection{Presentation of the research findings related to intervention}

\subsubsection{Care farming activities with animals}

In the first described study on animal-assisted interventions, by Berget et al. [26, 27], the treatment was 
not found to have any effect on depression, anxiety, and self-efficacy during the intervention period; however, a significant decrease in anxiety score and an increase in self-efficacy scores were found between the pre-treatment self-rated assessment and the six-month follow-up assessment. The participants with the largest reduction in depression reported the largest increases in perceived coping ability, mood, and self-esteem. Reported quality of life, however, showed no significant change or any significant differences between groups at any of the times it was measured [26]. A significant increase in coping ability within the treatment group was seen between the pre-treatment assessment and the six-month follow-up assessment; however, when compared with changes in the control group's assessments, no significant differences were found [26]. There was a significant increase in the intensity and exactness of the work the participants carried out with the animals by the end of the intervention. No significant correlations were found between physical contact with animals and changes in depression levels [28].

In the second described study, by Pedersen et al. [34], a statistically significant decline in depression levels between recruitment and the end of the intervention was observed in the intervention group but not in the control group. Six participants in the intervention group experienced a clinically significant change in depression levels, while just one in the control group did. During the same period of time, a positive and statistically significant change in self-efficacy occurred in the intervention group, but not in the control group. However, changes in mental health measures showed no statistically significant differences between the two groups.

The video recordings [35] show that time spent on work activities described as complex and challenging, like milking cows and moving animals between the cowshed and outdoor spaces, was significantly and favorably correlated with changes in mental health (depression and anxiety) but that there was an unfavorable correlation between time spent on work tasks that could be described as beginners' activities (like grooming animals and mucking) and positive changes in mental health. A favorable, significant association between dialogue with the farmer and changes in anxiety levels was detected.

In the interview study by Pedersen et al. [36], the possibility of being useful and the experience of an ordinary work setting were emphasized as important by the participants. The farmers' attitudes and sensitivity towards the participants' situations and illnesses were described as essential. The participants also expressed the importance of the intervention as a source of distraction from their illness. The intervention's flexibility was experienced as vital and as making it possible for the participants to adjust the work undertaken in relation to their daily condition. A majority of the participants expressed that they coped with the work tasks at the farm. This served as a foundation for other positive experiences, described as having increasing self-confidence, feeling independent, and learning new skills.

\subsubsection{Care farming with horticultural activities}

The results of the studies by Gonzalez et al. [38, 40] show a statistically significant decline in depression levels during the therapeutic horticulture intervention, with the most significant change occurring after four weeks. When compared to participants' pre-intervention measurements, this decline was still present and significant in a three-month follow-up assessment. Improvements in anxiety levels, positive affect, and perceived stress levels between the beginning and end of the intervention were all statistically significant [40]. Perceived attentional capacity increased significantly and perceived rumination decreased significantly during the intervention. Changes in depression levels and attentional capacity were mediated through being away from everyday environment and fascination [37]. The participants reported high levels of group cohesiveness, and the levels of group cohesiveness correlated positively, although not statistically significantly, with improvements in depression severity, anxiety levels, positive affect, and perceived stress levels. The participants positively evaluated the social aspects of the therapeutic horticulture intervention, and more than a third of the participants reported increased social activity after having participated in the intervention [39].

There were no significant changes in existential outcomes. There was, however, a positive correlation between changes in existential issues and changes in depression severity. The participants described their experience of and participation in the program as meaningful, interesting, and instructive. In the open-ended questions given at the end of the program, themes like excitement about and absorption in the growth process during the season were articulated. A vast majority of the participants agreed with statements regarding existential experiences of therapeutic horticulture: it was seen as a meaningful activity, gave a sense of taking care of nature, and changed their view of life [40]. 


\section{Discussion}

In the following, we will first discuss the main mental health outcomes across the presented interventions. We will then further discuss how participating in care farming may promote their health through improved self-efficacy and coping, as well as through the care farms' environmental and social context. Finally, we will point to design aspects that might guide future research.

\subsection{Mental health outcomes related to care farming}

Across the intervention studies here examined, participants experienced improvements in depression and anxiety levels, positive affect, perceived stress levels, and rumination. However, in the RCT study on animal-assisted intervention by Berget et al. [27], these improvements were only found in anxiety levels and were only observed during a six-month follow-up assessment. In the single-group studies by Gonzalez et al. $[37,38]$ on therapeutic horticulture, the decreases in participants' depression levels observed during the intervention remained present three months after the end of the intervention. Even though the improvements to most outcomes were small, the findings point to the possible mental health benefits for those suffering from mental health disorders of participating in care farm rehabilitation programs. The declines in depression reported by both Pedersen et al. [34] and Gonzalez et al. [37, 38] were both statistically and clinically significant, implying that the decline in depression is experienced by the study participant as an improvement in mental health. It is worth pointing out that this was observed across programs covering different farm-related occupations, like animal and horticultural activities. It is, however, important to bear in mind that for these studies, the recruited participants were to a large degree motivated to participate in care farming activities. For this reason, the findings are relevant only for a group of people suffering from depression and who are motivated for these kinds of interventions.

\subsection{Self-efficacy and coping related to work activities on care farms}

The studies presented here have, in particular, studied the benefits of care farming for mental health promotion in relation to self-efficacy and coping. Berget et al. $[26,28]$ found increased self-efficacy among participants placed at care farms, and they also observed increased intensity and exactness in the participants' work with the animals at the farm. In Pedersen et al. [35], a positive association between acquiring new and improved work skills and an increase in self-efficacy was seen as indicating an increase in engagement with the work. In the study by Pedersen et al. [36], the ability to cope with the given tasks was reported to be important for the participants, and this gave them an opportunity to develop their self-confidence. This is in line with the findings of other qualitative studies describing improved self-confidence and increased feeling of achievement as a result of participating in care farm activities [22, 23]. Hassink et al. [50] describe these kinds of interventions as empowermentoriented and coping-based from interviews with 41 clients, 33 care farmers, and 27 health care professionals. Positive coping experiences are associated with increased self-efficacy [48], and improved work skills and work-related self-efficacy is highlighted as important in several studies within vocational rehabilitation and mental health rehabilitation [7, 49-51]. There is a huge variation in the work tasks that can be carried out on a farm. Care farms make use of this variation to adapt the rehabilitation process to individual participants' physical and mental health and capacities on a day-to-day basis. The authors of this paper believe that the flexibility in possible occupations offered by the farm may be one of the key criteria for the observed increase in self-efficacy.

Through the care farm programs, the participant takes part in occupations that demand attention to daily routines, like getting up in the morning, being on time, calling to inform the farmer of one's absence, and, when possible, being responsible for their own transportation to the farm. Based on such aspects, clients describe their activities at the care farms as "natural" labor [52], and rehabilitation professionals emphasize that care farms are a suitable transitional work place, as they offer the possibility to enhance work and social skills, as well as motivating participants to try to reach further vocational goals [24].

\subsection{The care farms' environmental context}

Care farms are a complex intervention for promoting mental health with many possible acting components at stake. Apart from providing meaningful work tasks, they provide a natural environment in which to work. Gonzalez et al. [37] have used an environmental psychology and cognitive perspective, and they identified both a sense of being away from daily routines and 
tasks and a fascination with being in the intervention context as the active components of the therapeutic horticulture intervention at care farms. This implies that the change in environment, from the home to the farm (being away), and the experience of the farm and its horticultural activities as fascinating are important factors in explaining the observed decline in depression and improvement in perceived attentional capacity. It is anticipated that future studies will show that an improvement in perceived attentional capacity might both contribute to recovery processes and to improved coping resources. Further, both Gonzalez et al. [37] and qualitative studies on therapeutic horticulture interventions in other rehabilitation settings [51] point to gardening occupations as enjoyable in a safe environment and as contributing to a feeling of balance in everyday life.

\subsection{The care farms' social context}

Other common features of care farming interventions are group-related activities lead by the farmer. In the study by Gonzalez et al. [39], levels of group cohesiveness correlated positively with improvements in mental health and perceived stress. A majority of participants rated the social component of the intervention as important and reported a higher rate of social activity after the intervention. In the only qualitative article in this review by Pedersen et al. [36], being a colleague and sharing a considerate relationship with the farmer were themes brought forward by the participants as positive. In the same study, a favorable correlation between dialog with the farmer and a decrease in anxiety was detected [35]. Several studies on care farming highlight the group, the social setting, and the support of the farmer as important [20-23, 36, 52]. Leck et al. [15] describe a whole range of positive effects connected to the experience of social inclusion within a care farming context. Social support, social contact, and the development of social skills are fundamental for a successful mental health recovery process [53-55], and programs that facilitate the enhancement of social skills and provide social support are important during mental health and vocational rehabilitation [16]. Future research on care farming needs to consider the inclusion of outcome measures related to social support.

\subsection{Recommendations for further research}

The four intervention studies described above had a particular focus on either animal-assisted or therapeutic horticulture interventions, since previous research indicates the mental health benefits of these kind of interventions [56-58]. Even though nature experiences and activity connected to animals and/or horticulture are important at care farms, the studies do not examine all components of the care farm context, as care farming programs in Norway are complex in nature. Future studies should address this complexity. In addition, further studies should investigate the relevance of care farming for improvements in work skills, occupational function, and ultimately, work attendance or return to work rate.

Further, in vocational rehabilitation, randomized controlled trials are commonly conducted to compare different rehabilitation strategies [59-61]. A similar approach for comparing care farms with other transitional workplaces during vocational rehabilitation could be useful. In three of the studies, a homogenous target group was selected, namely people with depression. The selection of a single target group helps to focus the research questions but presents a challenge to the recruitment of participants. Further studies need to address these challenges in order to reach statistical validity.

\section{Conclusions}

Interventions at care farms provide a variety of opportunities for participants with mental health problems to engage in meaningful occupations. These experiences are connected with an improvement in mental health, self-efficacy, coping ability, and perceived attentional capacity. Participants' feeling of being away from their everyday environment, their fascination with the farm environment, their perception of good social support within the care farm environment, and their increase in social activity are reported as positive results of their participation. Taking into consideration the positive reported findings reviewed here, we can conclude that care farms as a place and care farming as an intervention program have potential as a supplementary approach in mental health rehabilitation and that participation on care farms helps to prepare people for a return to ordinary work.

\section{Acknowledgments}

We appreciate the invitation to present the present review on Norwegian intervention studies of care farming, and we are thankful to the editor and guest 
editors for their valuable comments on early drafts of the paper.

\section{References}

[1] Alonso J, Buron A, Bruffaerts R, He Y, Posada-Villa J, Lepine JP, Angermeyer MC, Levinson D, de Girolamo G, Tachimori H, Mneimneh ZN, Medina-Mora ME, Ormel J, Scott KM, Gureje O, Haro JM, Gluzman S, Lee S, Vilagut G, Kessler RC, Von Korff M. Association of perceived stigma and mood and anxiety disorders: Results from the World Mental Health Surveys. Acta Psychiatrica Scandinavica 2008;118(4):305-14.

[2] Alonso J, Angermeyer MC, Bernert S, Bruffaerts R, Brugha TS, Bryson H, de Girolamo G, Graaf R, Demyttenaere K, Gasquet I, Haro JM, Katz SJ, Kessler RC, Kovess V, Lepine JP, Ormel J, Polidori G, Russo LJ, Vilagut G, Almansa J, Arbabzadeh-Bouchez S, Autonell J, Bernal M, Buist-Bouwman MA, Codony M, Domingo-Salvany A, Ferrer M, Joo SS, Martinez-Alonso M, Matschinger $\mathrm{H}$, Mazzi F, Morgan Z, Morosini P, Palacin C, Romera B, Taub N, Vollebergh WA. Disability and quality of life impact of mental disorders in Europe: Results from the European Study of the Epidemiology of Mental Disorders (ESEMeD) project. Acta psychiatrica Scandinavica Supplementum 2004(420):38-46.

[3] Thesen J. Being a psychiatric patient in the communityreclassified as the stigmatized "other". Scandinavian Journal of Public Health 2001;29(4):248-55.

[4] Corrigan PW, Shapiro JR. Measuring the impact of programs that challenge the public stigma of mental illness. Clin Psychol Rev 2010;30(8):907-22.

[5] Harnois G, Gabriel P. Mental health and work: Impact, issues and good pratice. Geneva: World Health Organization, 2000.

[6] Sundsteigen B, Eklund K, Dahlin-Ivanoff S. Patients' experience of groups in outpatient mental health services and its significance for daily occupations. Scand J Occup Ther 2009;16(3):172-80.

[7] Dunn EC, Wewiorski NJ, Rogers ES. The meaning and importance of employment to people in recovery from serious mental illness: Results of a qualitative study. Psychiatric Rehabilitation Journal 2008;32(1):59-62.

[8] Liberman RP. Recovery from disability: Manual of psychiatric rehabilitation. Washington, D.C.: American Psychiatric Publ.; 2008.

[9] Bylsma LM, Taylor-Clift A, Rottenberg J. Emotional Reactivity to Daily Events in Major and Minor Depression. J Abnorm Psychol 2011;120(1):155-67.

[10] Harmon TM, Nelson RO, Hayes SC. Self-Monitoring of Mood Versus Activity by Depressed Clients. J Consult Clin Psych 1980;48(1):30-8.

[11] Rossler W. Psychiatric rehabilitation today: An overview. World Psychiatry 2006;5(3):151-7.

[12] Hillborg H, Svensson T, Danermark B. Towards a working life? Experiences in a rehabilitation process for people with psychiatric disabilities. Scand J Occup Ther 2010;17(2): 149-61.

[13] Hillborg H, Danermark B, Svensson T. Professionals' perceptions of and views about vocational rehabilitation for people with psychiatric disabilities. Work 2013;44(4):471-80.

[14] Lysaght RM, Larmour-Trode S. An exploration of social support as a factor in the return-to-work process. Work 2008;30(3):255-66.
[15] Leck C, Upton D, Evans N. Social Aspects of Green Care. In: Gallis C, editor. Green Care For Human Therapy, Social Innovation, Rural Economy, and Education. 1. New York: Nova Science Publishers, Inc; 2013, pp. 155-88.

[16] Michon HW, van Weeghel J, Kroon H, Schene AH. Personrelated predictors of employment outcomes after participation in psychiatric vocational rehabilitation programmes-a systematic review. Soc Psychiatry Psychiatr Epidemiol 2005;40(5):408-16.

[17] Kukla M, Bond GR. The working alliance and employment outcomes for people with severe mental illness enrolled in vocational programs. Rehabilitation Psychology 2009;54(2):157-63.

[18] Hassink J, van Dijk M, editors. Farming for health. Green-Care Farming Across Europe and the United States of America. Dortrecht: Springer; 2006.

[19] Sempik J, Hine R, Wilcox D, editors. Green Care: A Conseptual Framework. A Report of the Working Group on the Health Benefits of Green Care. COST 866, Green Care in Agriculture. Loughborough: Loughborough University; 2010.

[20] Berget B, Ekeberg O, Braastad BO. Attitudes to animalassisted therapy with farm animals among health staff and farmers. Journal of Psychiatric and Mental Health Nursing 2008;15(7):576-81.

[21] Bjørgen D, Johansen KJ. Bruker spør bruker, evaluering av Inn på tunet. Brukerevaluering av tilbud til mennesker med psykiske vansker i tre kommuner i Sør-Trøndelag. Mental helse i Sør- Trøndelag. Prosjektrapport I/2007, 2007.

[22] Elings M, Hassink J. Green Care Farms, A Safe Community Between Illness or Addiction and the Wider Society. International Journal of Therapeutic Communities 2008;29(3):310-22.

[23] Ketelaars D, Baars E, Kroon H. Healing trough working. A study of Therapeutic Communities for persons with Psychiatric Problems. New York, USA: Mercury Press; 2001.

[24] Iancu SC. New dynamics in mental health recovery and rehabilitation. The case of care farms. the Netherlands: Vrije; 2013.

[25] Haubenhofer DK, Elings M, Hassink J, Hine RE. The Development of Green Care in Western European Countries. Explore-Ny 2010;6(2):106-11.

[26] Berget B, Ekeberg O, Braastad BO. Animal-assisted therapy with farm animals for persons with psychiatric disorders: Effects on self-efficacy, coping ability and quality of life, a randomized controlled trial. Clinical practice and epidemiology in mental health. 2008; 4: http://www. cpementalhealth.com/content/4/1/9.

[27] Berget B, Ekeberg $\varnothing$, Pedersen I, Braastad BO. Animalassisted therapy with farm animals for persons with psychiatric disorders: Effects on anxiety and depression. A randomized controlled trial. Occupational Therapy in Mental Health 2011;27(2):50-64.

[28] Berget B, Skarsaune I, Ekeberg Ø, Braastad BO. Humans with Mental Disorders Working with Farm Animals: A Behavioral Study. Occupational Therapy in Mental Health 2007;23(2):101-17.

[29] Spielberger CD, Gorsuch RI, Lushene RE. Manual for the State-Trait Anxiety Inventory. Palo Alto, Ca: Consulting Psychologists Press; 1983.

[30] Beck A, Steer RA. Manual for the Beck Depression Inventory. San Antonio, TX: The Psychological Corporation; 1987.

[31] Wahl A, Burckhardt C, Wiklund I, Hanestad BR. The Norwegian version of the Quality of Life Scale (QOLS-N) - A validation and reliability study in patients suffering from psoriasis. Scand J Caring Sci 1998;12(4):215-22. 
[32] Schwarzer R, Jerusalem M. Generalized Self-Efficacy scale. In: Weinman J, Wright S, Johnston M, editors. Measures in health psychology: A user's portfolio Causal and control beliefs. Windsor: NFER-NELSON; 1995, pp. 35-7.

[33] Cooper CL, Sloan SJ, Williams S. Occupational Stress Indicator. England: NFER-Nelson; 1988.

[34] Pedersen I, Martinsen EW, Berget B, Braastad BO. Farm Animal-Assisted Intervention for People with Clinical Depression: A Randomized Controlled Trial. Anthrozoos 2012;25(2):149-60.

[35] Pedersen I, Nordaunet T, Martinsen EW, Berget B, Braastad BO. Farm Animal-Assisted Intervention: Relationship between Work and Contact with Farm Animals and Change in Depression, Anxiety and Self-efficacy among Persons with Clinical Depression. Issues in Mental Health Nursing 2011;32:493-500.

[36] Pedersen I, Ihlebaek C, Kirkevold M. Important elements in farm animal-assisted interventions for persons with clinical depression: A qualitative interview study. Disability and Rehabilitation 2012;34(18):1526-34.

[37] Gonzalez MT, Hartig T, Patil GG, Martinsen EW, Kirkevold M. Therapeutic horticulture in clinical depression: A prospective study of active components. J Adv Nurs 2010;66(9):2002-13.

[38] Gonzalez MT, Hartig T, Patil GG, Martinsen EW, Kirkevold M. Therapeutic horticulture in clinical depression: A prospective study. Research and Theory for Nursing Practice 2009;23(4):312-28.

[39] Gonzalez MT, Hartig T, Patil GG, Martinsen EW, Kirkevold M. A prospective study of group cohesiveness in therapeutic horticulture for clinical depression. International Journal of Mental Health Nursing 2011;20:119-29.

[40] Gonzalez MT, Hartig T, Patil GG, Martinsen EW, Kirkevold M. A Prospective Study of Existential Issues in Therapeutic Horticulture for Clinical Depression. Issues in Mental Health Nursing 2011;32(1):73-81.

[41] Cimprich B. Development of an Intervention to Restore Attention in Cancer-Patients. Cancer Nurs 1993;16(2):83-92.

[42] Hartig T, Korpela K, Evans GW, Garling T. A measure of restorative quality in environments. Scand Hous Plan Res 1997;14(4):175-94.

[43] Nolen-Hoeksema S, Morrow J. A prospective study of depression and posttraumatic stress symptoms after a natural disaster: The 1989 Loma Prieta Earthquake. J Pers Soc Psychol 1991;61(1):115-21.

[44] Cohen S, Kamarck T, Mermelstein R. A global measure of perceived stress. Journal of Health and Social Behavior 1983;24(4):385-96.

[45] Watson D, Clark LA, Tellegen A. Development and Validation of Brief Measures of Positive and Negative Affect - the Panas Scales. Journal of Personality and Social Psychology 1988;54(6):1063-70.

[46] Lese KP, MacNair-Semands RR. The therapeutic factors inventory: Development of a scale. Group 2000;24(4):303-17.

[47] Debats DL. Measurement of personal meaning: The psychometric properties of the Life Regard Index. In: Wong PTP,
Fry PS, editors. The human quest for meaning A hanbook of psychological research and clinical applications. Mahwah, NJ: Lawrence Erlbaum Associates; 1998, pp. 237-60.

[48] Antonovsky A. The structure and properties of the sense of coherence scale. Social Science \& Medicine 1993;36(6): 725-33.

[49] Callahan LF, Pincus T. The sense of coherence scale in patients with rheumatoid arthritis. Arthritis Care and Research 1995;8(1):28-35.

[50] Hassink J, Elings M, Zweekhorst M, van den Nieuwenhuizen N, Smit A. Care farms in the Netherlands: Attractive empowerment-oriented and strengths-based practices in the community. Health \& Place 2010;16(3):423-30.

[51] Eriksson T, Westerberg Y, Jonsson H. Experiences of women with stress-related ill health in a therapeutic gardening program. Can J Occup Ther 2011;78(5):273-81.

[52] Elings M. Effects of care farms. Scientific research on the benefits of care farms for clients. Wageningen UR, The Netherlands: Plant Research International, 2012.

[53] Hansson L. Determinants of quality of life in people with severe mental illness. Acta psychiatrica Scandinavica Supplementum 2006;(429):46-50.

[54] Kuehner C, Buerger C. Determinants of subjective quality of life in depressed patients: The role of self-esteem, response styles, and social support. Journal of Affective Disorders 2005;86(2-3):205-13.

[55] Ruesch P, Graf J, Meyer PC, Rossler W, Hell D. Occupation, social support and quality of life in persons with schizophrenic or affective disorders. Soc Psychiatry Psychiatr Epidemiol 2004;39(9):686-94.

[56] Rossetti J, King C. Use of Animal-Assisted Therapy with Psychiatric Patients: A Literature Review. Journal of Psychosocial Nursing \& Mental Health Services 2010;48(11):44-8.

[57] Souter MA, Miller MD. Do animal-assisted activities effectively treat depression? A meta-analysis. Anthrozoös 2007;20(2):167-80.

[58] Clatworthy J, Hinds J, Camic PM. Gardening as a mental health intervention: A review. Mental Health Review Journal 2013;18(4):214-25.

[59] Bond GR, Salyers MP, Dincin J, Drake R, Becker DR, Fraser $\mathrm{VV}$, Haines M. A randomized controlled trial comparing two vocational models for persons with severe mental illness. J Consult Clin Psychol 2007;75(6):968-82.

[60] Catty J, Lissouba P, White S, Becker T, Drake RE, Fioritti A, Knapp M, Lauber C, Rossler W, Tomov T, van Busschbach J, Wiersma D, Burns T. Predictors of employment for people with severe mental illness: Results of an international six-centre randomised controlled trial. The British Journal of Psychiatry 2008;192(3):224-31.

[61] Burns T, Catty J, White S, Becker T, Koletsi M, Fioritti A, Rossler W, Tomov T, van Busschbach J, Wiersma D, Lauber C. The impact of supported employment and working on clinical and social functioning: Results of an international study of individual placement and support. Schizophr Bull 2009;35(5):949-58. 